\title{
ARTHROPLASTY FOR TRAPEZIUM EXCISION AND TENDON INTERPOSITION IN RHIZARTHROSIS CASES: PROSPECTIVE STUDY
}

Walter Gomes Pinheiro Junior ${ }^{1}$, Renan Moukbel Chaim², Henrique Bella Freire de Carvalho ${ }^{3}$, Walter Manna Albertoni ${ }^{4}$, Flávio Faloppa ${ }^{5}$, João Baptista Gomes dos Santos ${ }^{6}$

\section{ABSTRACT}

Objective: To prospectively evaluate the results from a series of patients who underwent surgical treatment for rhizarthrosis using the technique of trapezium resection associated with interposition of yarn from the long abductor tendon of the thumb. Methods: From May to August 2005, ten patients underwent surgical treatment for rhizarthrosis. Patients with primary osteoarthrosis of the trapezium-metacarpal joint, in stages II, III and IV of the Eaton classification, with persistent pain that was refractory to clinical treatment, were included. For the functional assessment, the visual analogue scale, DASH questionnaire and Buck-Gramcko score were used. For the overall assessment on the patients, strength measurements were made for palm grip, pulp to pulp pinch, lateral pinch, three-point pinch, opposition and radial and palmar abductions. The migration index for the first metacarpal was also determined on radiographs at rest and under stress. Results: The pain relief was considered to be good ( $p=0.005)$, with functional improvements in modules $2(\mathrm{p}=0.02)$ and $3(\mathrm{p}=$ 0.022) of DASH. The Buck-Gramcko score showed one excellent and three very good results. There was an improvement in almost all of the overall assessment and was only non-significant regarding lateral pinch and abduction. For all patients, there was migration of the first metacarpal. Conclusion: Trapeziectomy associated with interposition of yarn from the long abductor tendon of the thumb was shown to be a relatively simple and effective technique for pain relief and functional improvement.

Keywords - Osteoarthritis; Thumb; Trapezium; Arthroplasty

\section{INTRODUCTION}

Osteoarthrosis of the trapezium-metacarpal joint of the thumb (rhizarthrosis) is a frequent disorder ${ }^{(1)}$. It occurs especially among postmenopausal women, but it is also observed among men with a history of repetitive use of this joint and among young women with conditions of ligament slackness ${ }^{(2)}$.

Rhizarthrosis of the thumb is caused by overloa- ding in the region of the spheroidal facet, which presents only a small contact area in retroposition, lateral pinching or opposition movements. This process can be accelerated if there is any association with ligament slackness that is primary or secondary to trauma or hormonal abnormalities ${ }^{(3,4)}$.

The initial clinical manifestation is localized pain at the base of the thumb, which is exacerbated by stress and sometimes accompanied by joint effu-

1 - Former Specialization Student in the Discipline of Hand and Upper Limb Surgery, Department of Orthopedics and Traumatology, Paulista School of Medicine, UNIFESP.

2 - Resident in the Orthopedics Program, Paulista School of Medicine, UNIFESP.

3 - Resident in the Orthopedics Program, Paulista School of Medicine, UNIFESP.

4 - Titular Professor of the Department of Orthopedics and Traumatology, Paulista School of Medicine, UNIFESP. Rector of UNIFESP.

5 - Titular Professor of the Department of Orthopedics and Traumatology, Paulista School of Medicine, UNIFESP.

6 - Adjunct Professor and Head of the Discipline of Hand and Upper Limb Surgery, Department of Orthopedics and Traumatology, Paulista School of Medicine, UNIFESP.

Correspondence: Rua Borges Lagoa 786 - Vila Clementino - 04038-032 - São Paulo, SP. E-mail: renanmchaim@yahoo.com.br

Work received for publication: July 20, 2010; accepted for publication: November 3, 2010. 
sion $^{(5)}$. Patients report incapacity to perform activities of day-to-day life, such as domestic tasks, sports and leisure activities.

The initial treatment is conservative and includes rest, use of orthoses, use of non-hormonal anti-inflammatory agents, infiltration using glucocorticoids and physiotherapy $^{(6)}$. Pain caused by degeneration of the trapezium-metacarpal joint is a frequent problem, and surgery becomes the choice when the symptoms are refractory to clinical treatment.

Several types of surgical treatment have shown good results in the literature ${ }^{(2,7-14)}$. The aim of the present study was to present the results from a prospective series of 10 patients who underwent simple resection of the trapezium in association with interposition of yarn from the long abductor tendon of the thumb.

\section{METHODS}

This study and its consent statement were approved by our institution's research ethics committee.

Patients with a diagnosis of primary osteoarthrosis of the trapezium-metacarpal joint in association with complaints of persistent pain that was refractory to clinical treatment were included. After the patients had been included in the study, they underwent trapeziectomy with interposition of yarn from the long abductor tendon of the thumb, between May and August 2005. Patients with rheumatoid arthritis and posttraumatic patients were excluded.
Table 1 demonstrates the preoperative data on the patients, according to the chronological order of the procedures. The following were described: age, in years; sex; color; side operated; symptoms of the opposite side; dominant hand; profession; time elapsed between the start of symptoms and the surgery, in months; type of previous treatment; and radiographic classification according to Eaton and Littler ${ }^{(7)}$.

To assess subjective functional outcomes, the DASH (Disabilities of the Arm, Shoulder and Hand) questionnaire was applied ${ }^{(15)}$. This instrument consists of three modules of questions relating to daily activities. The first two were occupational: sport or musical instrument and work, both with four questions; and a third, general module with 30 questions. If the patient did not practice sports, did not play musical instruments or did not work, he would receive a score of zero in the corresponding module. To evaluate the outcome of pain, a visual analogue scale (VAS) was used. VAS and DASH were applied prior to the surgery and at the end of the follow-up.

The following were measured: palm grip strength (Jamar ${ }^{\circledR}$ dynamometer), fingertip to thumb tip pinch grip, lateral pinch grip, three-point pinch grip (B\&L Engineering ${ }^{\circledR}$ pinch dynamometer); thumb opposition using the Kapandji method ${ }^{(16)}$; and radial and palmar abduction using a goniometer. At the end of the follow-up, the Buck-Gramcko score was applied ${ }^{(17)}$. This uses objective data (fingertip to thumb tip grip

Table 1 - General preoperative data on the patients with rhizarthrosis.

\begin{tabular}{|c|c|c|c|c|c|c|c|c|c|c|}
\hline Patient & Age & Sex & Color & $\begin{array}{l}\text { Side } \\
\text { op }\end{array}$ & Bilat & $\begin{array}{l}\text { Dom } \\
\text { side }\end{array}$ & Profession & $\begin{array}{l}\text { Time with } \\
\text { symptoms }\end{array}$ & $\begin{array}{l}\text { Previous } \\
\text { treatment }\end{array}$ & Classification \\
\hline 1 & 55 & $\mathrm{~F}$ & NW & $L$ & No & $\mathrm{R}$ & Housewife & 24 & $A+O$ & III \\
\hline 2 & 48 & $\mathrm{~F}$ & W & $L$ & Yes & $\mathrm{R}$ & Manicurist & 36 & $A+O+1$ & III \\
\hline 3 & 51 & $\mathrm{~F}$ & W & $L$ & Yes & $\mathrm{R}$ & Housewife & 36 & $A+P$ & IV \\
\hline 4 & 53 & $\mathrm{~F}$ & W & $\mathrm{R}$ & Yes & $\mathrm{R}$ & Sociologist & 48 & $A+P+I$ & III \\
\hline 5 & 46 & $\mathrm{~F}$ & NW & $\mathrm{R}$ & No & $\mathrm{R}$ & Housewife & 58 & $A+P$ & III \\
\hline 6 & 49 & $\mathrm{~F}$ & W & $L$ & No & $\mathrm{R}$ & Housewife & 24 & $A+1$ & III \\
\hline 7 & 68 & $\mathrm{~F}$ & W & $\mathrm{R}$ & No & $\mathrm{R}$ & Seamstress & 36 & $A+I+P+O$ & II \\
\hline 8 & 78 & $\mathrm{~F}$ & W & $L$ & Yes & $\mathrm{R}$ & Housewife & 12 & $A+O$ & IV \\
\hline 9 & 54 & $\mathrm{~F}$ & W & $\mathrm{R}$ & Yes & $\mathrm{R}$ & Retired & 15 & $A+P$ & III \\
\hline 10 & 65 & $M$ & NW & $\mathrm{L}$ & No & $\mathrm{R}$ & Retired & 24 & $A+I$ & III \\
\hline
\end{tabular}

$\mathrm{F}=$ female; $\mathrm{M}=$ male; $\mathrm{NW}=$ nonwhite $\mathrm{W}=$ white; Side op = side operated; Dom side = dominant side;

$\mathrm{L}=$ left $\mathrm{R}=$ right; Time with symptoms in months; $\mathrm{A}=$ anti-inflammatory agents; $\mathrm{O}=$ orthosis;

$\mathrm{I}=$ infiltration with glucocorticoid; $\mathrm{P}=$ physiotherapy; Bilat = bilaterality.

Rev Bras Ortop. 2011;46(1):75-82 
strength and palmar and radial abduction) and subjective data (questionnaire on pain, strength, daily activities, dexterity, cosmetic appearance, satisfaction with the procedure and a general assessment), which are scored and summed, resulting in the following classification: excellent, from 49 to 56 points; good, from 40 to 48 points; fair, from 28 to 39 points; and poor, less than 28 points.

Through the standardized position of the hand on the frame, radiographs were produced to calculate the preoperative trapezoidal space index. In the final assessment, the index of migration from the first metacarpal was calculated, at rest and under stress (key pinch), dividing the distance between the distal pole of the scaphoid and the base of the first metacarpal by the length of the first metacarpal (Yang and Weiland method) $)^{(18)}$.

\section{SURGICAL TECHNIQUE}

All the patients were operated under brachial plexus block, using a pneumatic tourniquet. One dorsal-radial access of zigzag type and another proximal transverse access were made. The trapezium-metacarpal joint capsule was opened longitudinally as two flaps, which were used for closure, and the trapezium bone was dried out (Figure 1). The first extensor compartment was opened. From one of the accessory tendons of the long abductor of the thumb, or if it was the only one, with a strip from this, yarn was prepared and put into the defect created through resection of the trapezium (Figure 2). Next, fixation

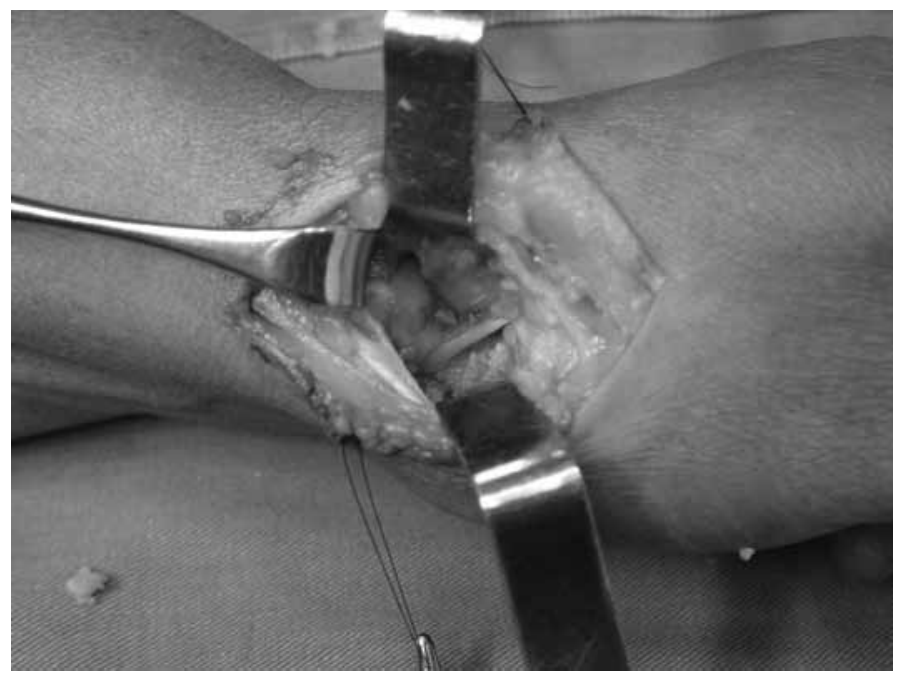

Figure 1 - Excision of trapezium bone. in radial abduction from the first to the second metacarpal was performed using $1.5 \mathrm{~mm}$ Kirschner wire (Figure 3). The joint capsule was closed using 3-0 absorbable thread and the tourniquet was released to reach hemostasis. The skin was sutured with 5-0 nylon thread and the area was immobilized by means of a plaster cast up to the thumb.

The suture stitches were removed one week later and the patient was kept immobilized for another three weeks. The Kirschner wires were then removed and the patient was sent for rehabilitation. An orthosis to maintain the radial abduction was used at night for an additional period of two months.

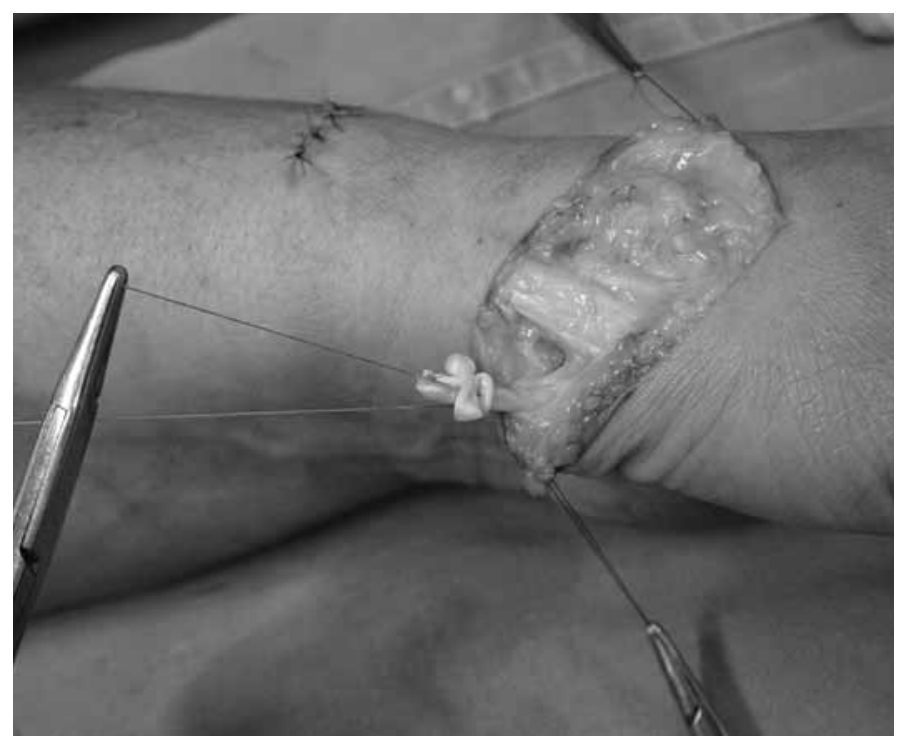

Figure 2 - Yarn from long abductor of the thumb.

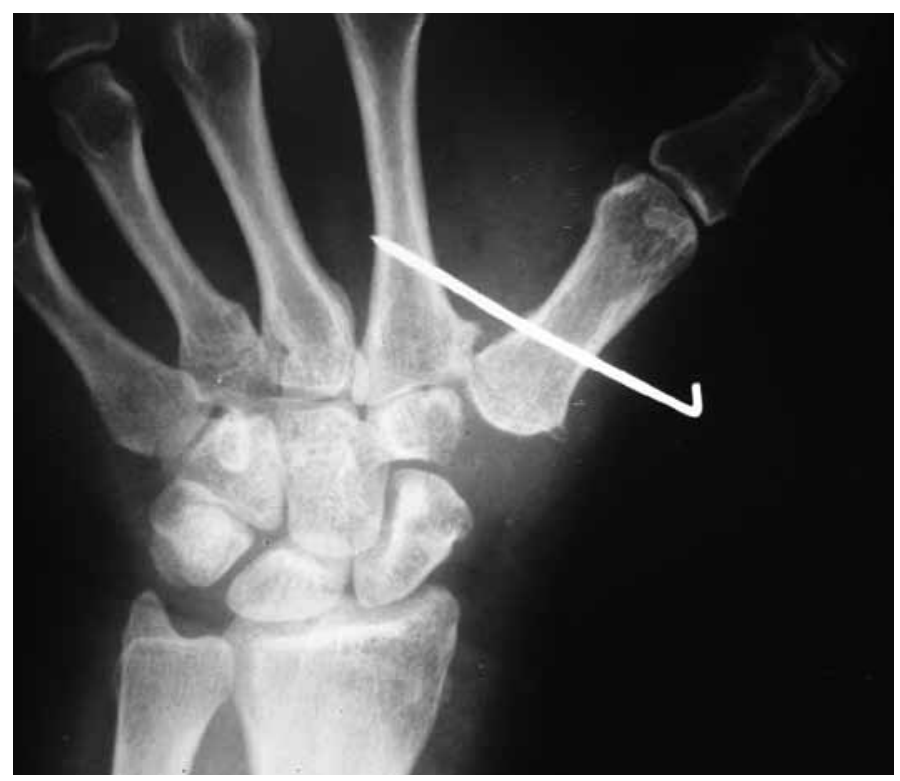

Figure 3 - Postoperative radiograph in pos $\neg$ te $\neg$ roanterior view. 


\section{STATISTICAL ANALYSIS}

Inferential analysis on the pre and postoperative means was performed on the non-categorical data using the non-parametric Wilcoxon Signed Ranks test, since these were correlated samples. Descriptive analysis was done using central trend measurements and their respective standard deviations.

\section{RESULTS}

Ten patients who underwent the surgical procedure were included and followed up over a mean period of 41.6 months.

Table 2 demonstrates the preoperative and postoperative functional results from the DASH question-

Table 2 - Evaluation of the modules of the DASH questionnaire before and after the operation.

\begin{tabular}{c|c|c|c|c|c|c}
\hline Patient & $\begin{array}{c}\text { M1 } \\
\text { before }\end{array}$ & $\begin{array}{c}\text { M1 } \\
\text { after }\end{array}$ & $\begin{array}{c}\text { M2 } \\
\text { before }\end{array}$ & $\begin{array}{c}\text { M2 } \\
\text { after }\end{array}$ & $\begin{array}{c}\text { M3 } \\
\text { before }\end{array}$ & $\begin{array}{c}\text { M3 } \\
\text { after }\end{array}$ \\
\hline 1 & 0 & 0 & 75 & 50 & 45.83 & 30 \\
\hline 2 & 0 & 0 & 43.75 & 62.5 & 32.5 & 58.33 \\
\hline 3 & 0 & 0 & 62.5 & 6.25 & 52.5 & 6.66 \\
\hline 4 & 0 & 43.75 & 18.75 & 37.5 & 64.16 & 44.16 \\
\hline 5 & 0 & 0 & 75 & 18.75 & 42.5 & 15.83 \\
\hline 6 & 100 & 0 & 68.75 & 18.75 & 41.66 & 1.66 \\
\hline 7 & 0 & 0 & 0 & 0 & 49.16 & 0.83 \\
\hline 8 & 0 & 0 & 62.5 & 18.75 & 42.5 & 1.66 \\
\hline 9 & 0 & 50 & 100 & 50 & 63.33 & 49.16 \\
\hline 10 & 68.75 & 0 & 62.5 & 18.75 & 37.5 & 15.83 \\
\hline Mean & 16.88 & 9.37 & 56.88 & 28.12 & 43.66 & 22.41 \\
\hline
\end{tabular}

M1 - module 1 of the questionnaire; M2 - module 2 of the questionnaire; M3 - module 3 of the questionnaire naire. Functional improvements in all three modules were observed. However, the inferential statistical analysis showed that there was no statistically significant difference in DASH module 1 from before to after the operation $(\mathrm{p}=0.463)$. On the other hand, module $2(p=0.020)$ and module $3(p=0.022)$ both showed statistical differences from before to after the operation.

Table 3 shows the results from the Buck-Gramcko scores. Out of the 10 patients assessed, one patient was found to have an excellent result at the end of the follow-up, while three patients had good results and six had fair results.

Table 4 shows the results from the visual pain scale. The statistical analysis showed that there was a

Table 4 - Visual pain scale.

\begin{tabular}{c|c|c}
\hline Patient & Before operation & After operation \\
\hline 1 & 7.5 & 2.8 \\
\hline 2 & 10 & 7 \\
\hline 3 & 5 & 0 \\
\hline 4 & 7 & 3.1 \\
\hline 5 & 7 & 3 \\
\hline 6 & 7 & 0 \\
\hline 7 & 9 & 0 \\
\hline 8 & 7.2 & 0 \\
\hline 9 & 10 & 1.5 \\
\hline 10 & 8 & 2.04 \\
\hline mean & 7.77 &
\end{tabular}

Table 3 - Buck-Gramcko scores for the objective and subjective data at the end of the follow-up.

\begin{tabular}{|c|c|c|c|c|c|c|c|c|c|c|c|c|}
\hline Patient & PA & RA & PP & Pain & Strength & ADL & Dexterity & Cosmetic & Again & General assessment & Total & Result \\
\hline 1 & 6 & 6 & 6 & 4 & 3 & 2 & 0 & 3 & 0 & 4 & 34 & Fair \\
\hline 2 & 6 & 6 & 0 & 2 & 3 & 2 & 3 & 4 & 4 & 2 & 32 & Fair \\
\hline 3 & 6 & 4 & 6 & 6 & 6 & 6 & 6 & 4 & 4 & 6 & 54 & Excellent \\
\hline 4 & 6 & 6 & 6 & 4 & 0 & 2 & 3 & 2 & 4 & 4 & 37 & Fair \\
\hline 5 & 6 & 6 & 4 & 4 & 3 & 4 & 3 & 2 & 4 & 4 & 40 & Good \\
\hline 6 & 6 & 6 & 0 & 6 & 6 & 6 & 6 & 2 & 0 & 4 & 42 & Good \\
\hline 7 & 6 & 6 & 4 & 6 & 3 & 6 & 3 & 3 & 4 & 6 & 47 & Good \\
\hline 8 & 2 & 4 & 0 & 6 & 0 & 6 & 4 & 4 & 4 & 6 & 36 & Fair \\
\hline 9 & 6 & 6 & 4 & 4 & 0 & 6 & 0 & 4 & 4 & 4 & 38 & Fair \\
\hline 10 & 4 & 6 & 4 & 2 & 3 & 6 & 0 & 3 & 0 & 2 & 30 & Fair \\
\hline Mean & 5.4 & 5.6 & 3.4 & 4.4 & 2.7 & 4.6 & 2.8 & 3.1 & 2.8 & 4.2 & 39 & \\
\hline
\end{tabular}

$\mathrm{PA}=$ palmar abduction; $\mathrm{RA}=$ radial abduction; $\mathrm{ADL}=$ activities of daily living;

Again = would you undergo this surgery again? 
significant different from before to after the operation $(p=0.005)$, representing a marked improvement.

The objective data were also compared before and after the operation. The palm grip strength after the operation was lower, with a statistically significant difference $(p=0.033)$. The fingertip to thumb tip pinch strength $(\mathrm{p}=0.024)$, three-point pinch strength $(p=0.038)$, radial abduction $(p=0.005)$ and palmar abduction $(\mathrm{p}=0.005)$ presented improvements after the operation, with statistical significance. The lateral pinch strength $(p=0.136)$ was greater after the operation, but without any statistical significance. The difference in opposition was also non-significant $(\mathrm{p}=0.123)$, with the postoperative value slightly lower. These data are demonstrated in Table 5.

All ten patients presented proximal migration of the first metacarpal. In three patients, the space between the scaphoid and the base of the metacarpal disappeared completely during the radiograph under stress (Figures 4, 5 and 6).

The complications observed were: paresthesia of the radial sensory nerve in four patients, with improvement after three months; and early loosening of the Kirschner wires (after four weeks) in one patient, who was then kept immobilized for a further week.

\section{DISCUSSION}

The results from the various surgical techniques for treating rhizarthrosis are controversial in the literature $^{(8-14,19-, 24)}$.
In 1949, Gervis $^{(9)}$ described excision of the trapezium for patients who were not responsive to conservative clinical treatment, and observed good results regarding pain relief. However, subsequent reports on Gervis's surgical procedure, by Murley ${ }^{(25)}$ and Iyer ${ }^{(26)}$ observed considerable weakness, which could be attributed to instability of the base of the metacarpal. This observation resulted in development of the concept of ligament reconstruction to stabilize the base of the metacarpal, which was put forward by Eaton and Littler in $1973^{(7)}$. A study by Burton and Pellegrini published in $1986^{(11)}$ popularized the procedure known by the acronym LRTI (ligament reconstruction and tendon interposition). In the literature, the results reported by these and other investigators are very $\operatorname{good}^{(19,20)}$. LRTI includes various ways of stabilizing the base of the metacarpal of the thumb, as follows: 1) ligament reconstruction, using a strip from the radial flexor tendon of the carpus; 2) interposition of the tendon in the space of the trapeziectomy; 3 ) temporary fixation using Kirschner wires and, in addition, immobilization of the thumb after the surgery.

Over the years, several investigators have put aside the notion that all forms of stabilization should be used together. Froimson ${ }^{(21)}$, Dell and Muniz ${ }^{(22)}$ and other authors have suggested that tendon interposition without ligament reconstruction or temporary fixation with Kirschner wires is sufficient. Gerwin et al ${ }^{(23)}$ showed that the results from ligament reconstruction are not affected by interposition of the tendon. In a

Table 5 - Overall assessment on the patients who were operated.

\begin{tabular}{|c|c|c|c|c|c|c|c|c|c|c|c|c|c|c|}
\hline \multirow{2}{*}{ Patient } & \multicolumn{2}{|c|}{$P G$} & \multicolumn{2}{|c|}{ TTP } & \multicolumn{2}{|c|}{ LP } & \multicolumn{2}{|c|}{ 3PP } & \multicolumn{2}{|c|}{ RA } & \multicolumn{2}{|c|}{ PA } & \multicolumn{2}{|c|}{ OP } \\
\hline & Before & After & Before & After & Before & After & Before & After & Before & After & Before & After & Before & After \\
\hline 1 & 26.0 & 15.0 & 2.5 & 8.0 & 5.0 & 10.0 & 4.0 & 9.0 & 28.0 & 42.0 & 28.0 & 42.0 & 10.0 & 9.0 \\
\hline 2 & 26.0 & 0.0 & 3.5 & 2.0 & 3.5 & 3.0 & 3.0 & 2.0 & 30.0 & 44.0 & 40.0 & 42.0 & 10.0 & 9.0 \\
\hline 3 & 16.0 & 8.0 & 3.5 & 9.0 & 5.0 & 12.0 & 3.5 & 10.0 & 34.0 & 38.0 & 34.0 & 40.0 & 9.0 & 8.0 \\
\hline 4 & 18.0 & 12.0 & 3.0 & 8.0 & 3.0 & 8.0 & 2.5 & 7.0 & 34.0 & 40.0 & 32.0 & 42.0 & 10.0 & 10.0 \\
\hline 5 & 26.0 & 12.0 & 5.0 & 5.0 & 6.0 & 6.0 & 5.0 & 4.5 & 30.0 & 40.0 & 30.0 & 42.0 & 9.0 & 9.0 \\
\hline 6 & 20.0 & 12.0 & 3.5 & 5.0 & 4.0 & 9.0 & 3.5 & 6.0 & 38.0 & 40.0 & 40.0 & 42.0 & 10.0 & 8.0 \\
\hline 7 & 12.0 & 12.0 & 3.0 & 5.0 & 5.0 & 4.5 & 4.5 & 5.0 & 30.0 & 44.0 & 30.0 & 42.0 & 9.0 & 6.0 \\
\hline 8 & 4.0 & 2.0 & 3.0 & 2.5 & 3.0 & 2.5 & 3.0 & 3.0 & 15.0 & 35.0 & 18.0 & 25.0 & 8.0 & 6.0 \\
\hline 9 & 12.0 & 16.0 & 3.0 & 6.0 & 3.5 & 6.0 & 3.0 & 4.0 & 35.0 & 40.0 & 32.0 & 40.0 & 10.0 & 10.0 \\
\hline 10 & 22.0 & 24.0 & 3.0 & 5.0 & 7.0 & 5.0 & 3.0 & 5.0 & 28.0 & 40.0 & 36.0 & 38.0 & 8.0 & 10.0 \\
\hline Mean & 18.2 & 11.3 & 3.3 & 5.5 & 4.5 & 6.6 & 3.5 & 4.6 & 30.2 & 40.3 & 32.0 & 39.5 & 9.3 & 8.5 \\
\hline
\end{tabular}

PG: palm grip strength in kgf (kilograms-force); TTP: fingertip to thumb tip pinch strength in kgf; LP: lateral pinch strength in kgf; 3PP: three-point pinch strength in kgf; RA: radial abduction in degrees; PA: palmar abduction in degrees; OP: opposition 


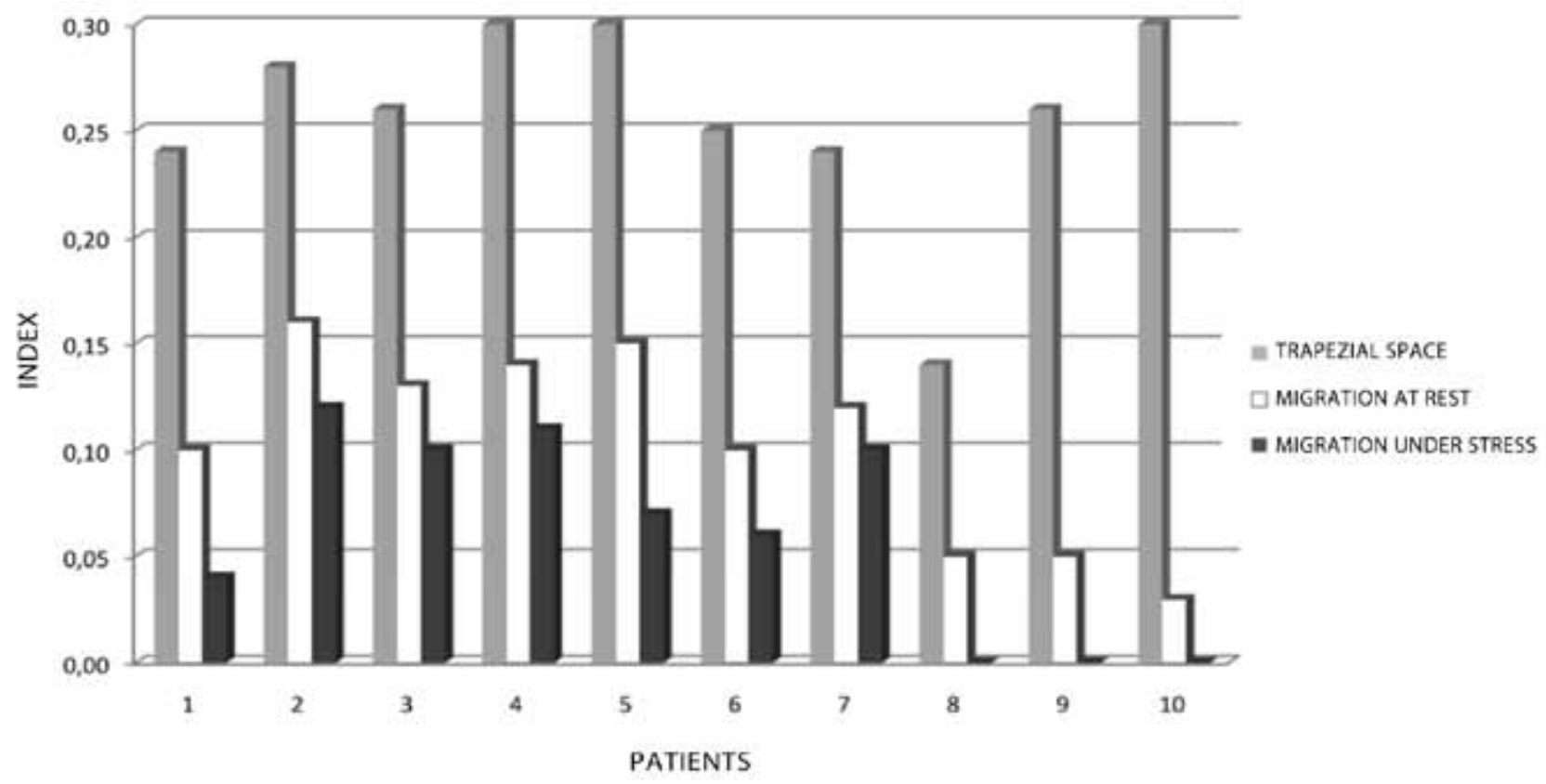

Figure 4 - Indices for trapezial space and migration of the first metacarpal, at rest and under stress, for patients 1 to 10.

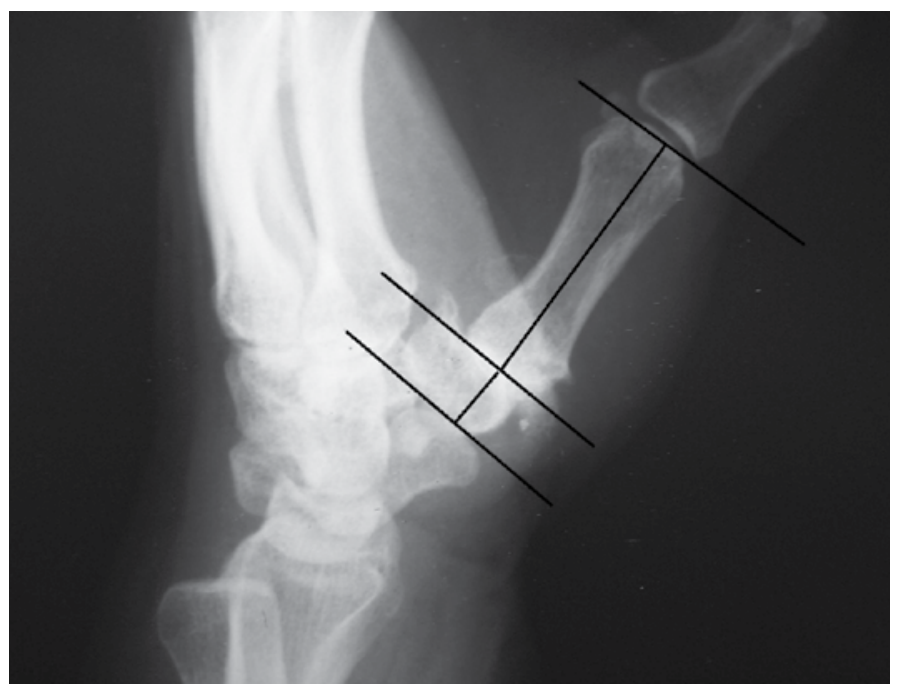

Figure 5 - Radiograph showing the method for measuring the trapezial space and the first metacarpal.

recent study published by Kuhns et $\mathrm{al}^{(24)}$, it was demonstrated that stabilization with Kirschner wires was enough for stabilization of the trapezium-metacarpal joint, which was also observed in the randomized prospective study by Davis et $\mathrm{al}^{(10)}$.

The patients presented in this study represent the population typically affected by primary osteoarthrosis of the trapezium-metacarpal joint, with regard to age, sex, color and profession, as shown by data reported in the literature ${ }^{(1,2,8,9,10,12)}$.

Regarding pain relief, just as in other stu-

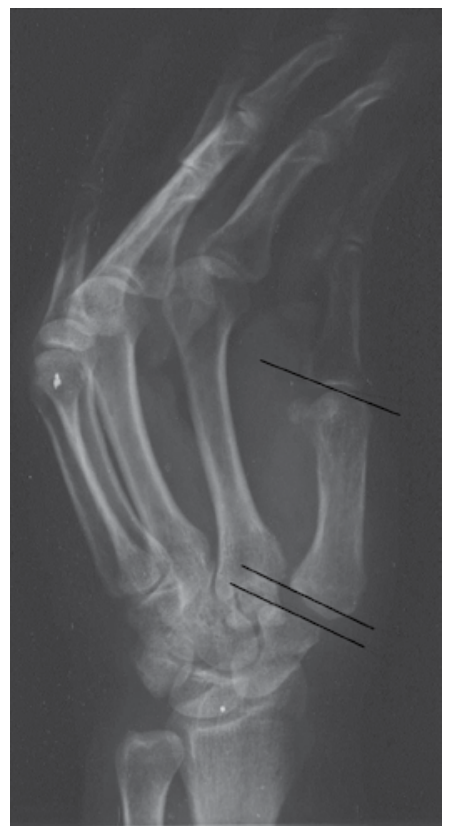

Figure 6 - Postoperative radiograph showing the migration of the metacarpal during maximum stress of lateral pinch.

$\operatorname{dies}^{(2,7-10,12,21,23,25,26)}$, there was an improvement in relation to the preoperative level, with patients becoming free from painful symptoms after the operation. This can probably be correlated with the excision of the trapezium and its arthritic joint.

In analyzing the effect of the surgery on physical function, we found studies in the literature ${ }^{(19,20)}$ that used subjective data involving daily activities that 
caused pain and caused functional limitations, such as: turning a key, opening a jar, counting money, writing, using a knife or scissors, fastening buttons on clothes, brushing teeth and picking up small objects, among others. However, these were used without standardization that might facilitate comparisons between results. Among the functional scales that are available for functional assessment are the Jebsen Hand Function Test ${ }^{(27)}$, Sollerman Test of Hand Function ${ }^{(28)}$ and $\mathrm{DASH}^{(15)}$. This last one was recently validated within our setting and was used in our study.

With regard to methods for overall assessments on patients, the literature ${ }^{(1,2,9,10,12-14,19-22)}$ includes strength measurements (palm grip, fingertip to thumb tip pinch, key pinch and three-point pinch), goniometry (palmar and radial abduction) and opposition. These have demonstrated improvements in results after a minimum of two years of follow-up, in comparison with preoperative findings. In our study, a loss of strength was observed in relation to palm grip, but there were gains in fingertip to thumb tip pinch, lateral pinch and three-point pinch. Improvement in the goniometry was observed (palmar and radial abduction), in line with data in the literature. Some patients presented deficits of opposition after the operation, while others remained unaltered and yet others achieved improvement in this respect.

Like in the randomized prospective study by Kriegs, we used the Buck-Gramcko score to obtain a final result from the procedure, with associations of objective and subjective data, thereby enabling comparison with other assessment methods that have been used and other techniques in future studies. It needs to be emphasized that in the Buck-Gramcko score ${ }^{(17)}$, the objective data are responsible for a maximum total of 18 points $(32 \%)$, while the total for the subjective data is a maximum of 38 points $(68 \%)$, out of the total of 56 points. It should also be noted that in the objective data, the fingertip to thumb tip pinch strength was compared with the contralateral side, without taking dominance and bilaterality into consideration. The minimum necessary for achieving an excellent result is 49 points.

In relation to tendon interposition, although studies have not shown differences in the clinical results $^{(10,20,22)}$, we believe that using a portion of the long abductor of the thumb reduces the deforming forces that act on the base of the first metacarpal, and that the interposition simulates a biological effect that induces fibrosis and thus produces a pad between the incongruent surfaces of the base of the metacarpal and the distal surface of the scaphoid.

With regard to postoperative fixation and immobilization, we implemented temporary fixation for five weeks using Kirschner wires associated with a plaster cast up to the thumb, thereby making it possible for soft tissues to heal, so that rehabilitation could be started with some stability. In the literature, the time taken for removal of the fixation and for immobilization has ranged from four to six weeks ${ }^{(5,7,8,10,11,20,22-24)}$.

The radiographic study showed that there was proximal migration of the first metacarpal $(\geq 50 \%)$ in all the patients. In three of them, the space between the first metacarpal and the scaphoid disappeared under stress, while the Buck-Gramcko score showed that these three had fair results, with significant improvements in their assessments according to DASH. It was concluded that the proximal migration of the first metacarpal and consequent loss of thumb length did not affect the functional result in our study, and this has also been reported in the literature ${ }^{(10,20)}$.

We also observed that despite the loss of grip strength in the tests using a dynamometer after the surgery, this did not influence the clinical and functional results.

All the studies that have demonstrated results as satisfactory as those described by Burton and Pellegrini ${ }^{(11)}$ used plaster, orthoses or bandaging for three to four weeks after the operation, for immobilization. In a comment on excision of the trapezium, Manske ${ }^{(29)}$ speculated that the unsatisfactory results found by Gervis ${ }^{(9)}$ and subsequently by Murley ${ }^{(25)}$ and Iyer $^{(26)}$ could have been improved through simple postoperative immobilization of the thumb. Within our setting, Pardini Junior et $\mathrm{al}^{(30)}$ confirmed that addition of ligamentoplasty to trapeziectomy with interposition did not present any advantages. We did not find in the literature any studies that prospectively analyzed surgical treatment with such variables.

We are not advocating totally abandoning stabilization techniques such as suspensionplasty and ligament reconstruction but, rather, we have sought to determine better indications for such techniques and to find their real value in the final result from the treatment. 


\section{CONCLUSION}

Trapeziectomy with interposition of a strip from the long abductor of the thumb was shown to be a technique that could be performed relatively easily. The results showed that the technique was effective for pain relief and clinical and functional improvement in most of the patients.

\section{REFERENCES}

1. Armstrong $A L$, Hunter JB, Davis TR. The prevalence of degenerative arthritis of the base of the thumb in post-menopausal women. J Hand Surg Br. 1994;19(3):340-1.

2. Martou G, Veltri K, Thoma A. Surgical treatment of osteoarthritis of the carpometacarpal joint of the thumb: a systematic review. Plast Reconstr Surg. 2004;114(2):421-32

3. Zancolli EA, Ziadenberg C, Zancolli E Jr. Biomechanics of the trapeziometacarpal joint. Clin Orthop Relat Res. 1987;(220):14-26.

4. Zancolli, EC, Cozzi EP. "Articulación trapeciometacarpiana (anatomia y mecánica)". In: Atlas de anatomia quirúrgica de la mano. Buenos Aires: Ed. Buenos Aires; 1994. p. 493-510.

5. Eaton RG, Glickel SZ, Littler JW. Tendon interposition arthroplasty for degenerative arthritis of the trapeziometacarpal joint of the thumb. J Hand Surg Am. 1985;10(5):645-54.

6. Swigart CR, Eaton RG, Glickel SZ, Johnson C. Splinting in the treatment of arthritis of the first carpometacarpal joint. J Hand Surg Am. 1999;24(1):86-91.

7. Eaton RG, Littler JW. Ligament reconstruction for the painful thumb carpometacarpal joint. J Bone Joint Surg Am. 1973;55(8):1655-66.

8. Thompson JS. Suspensioplasty. J Orthop Surg Technol. 1989;41(1):1-13.

9. Gervis WH. Excision of the trapezium for osteoarthritis of the trapezio-metacarpal joint. J Bone Joint Surg Br. 1949;31(4):537-9.

10. Davis TR, Brady O, Dias JJ. Excision of the trapezium for osteoarthritis of the trapeziometacarpal joint: a study of the benefit of ligament reconstruction or tendon interposition. J Hand Surg Am. 2004;29(6):1069-77.

11. Burton RI, Pellegrini VD Jr. Surgical management of basal joint arthritis of the thumb. Part II. Ligament reconstruction with tendon interposition arthroplasty. J Hand Surg Am. 1986;11(3):324-32.

12. Wajon A, Ada L, Edmunds I. Surgery for thumb (trapeziometacarpal joint) osteoarthritis. Cochrane Database Syst Rev. 2005;(4):CD004631.

13. Thomsen $\mathrm{NO}$, Jensen $\mathrm{CH}$, Nygaard $\mathrm{H}$. Weilby-Burton arthroplasty of the trapeziometacarpal joint of the thumb. Scand J Plast Reconstr Surg Hand Surg. 2000;34(3):253-6.

14. Ishida O, Ikuta Y. Trapeziometacarpal joint arthrodesis for the treatment of arthrosis. Scand J Plast Reconstr Surg Hand Surg. 2000;34(3):245-8.

15. Orfale AG, Araújo PM, Ferraz MB, Natour J. Translation into Brazilian Portuguese, cultural adaptation and evaluation of the reliability of the Disabilities of the Arm, Shoulder and Hand Questionnaire. Braz J Med Biol Res.2005;38(2):293302.

16. Kapandji A. [Clinical test of apposition and counter-apposition of the thumb]. Ann Chir Main. 1986;5(1):67-73.
17. Buck-Gramcko D. Bewertung der Ergebnisse von Operationen wegen Daumensattelgelenksarthrose. Rundschreiben an die Teilnehmer der XII. Basler Handchirurgischen Arbeitstagung, Marz 1987. In: Buck-Gramcko d, Heilbig B, editors. Daumensattelgelenksarthrose. Stuttgart: Hippokrates; 1994. p. 43-4.

18. Yang SS, Weiland AJ. First metacarpal subsidence during pinch after ligament reconstruction and tendon interposition basal joint arthroplasty of the thumb. J Hand Surg Am. 1998;23(5):879-83.

19. Tomaino MM, Pellegrini VD Jr, Burton RI. Arthroplasty of the basal joint of the thumb. Long-term follow-up after ligament reconstruction with tendon interposition. J Bone Joint Surg Am. 1995;77(3):346-55.

20. Kriegs-Au G, Petje G, Fojtl E, Ganger R, Zachs I. Ligament reconstruction with or without tendon interposition to treat primary thumb carpometacarpal osteoarthritis. A prospective randomized study. J Bone Joint Surg Am. 2004;86$A(2): 209-18$

21. Froimson Al. Tendon arthroplasty of the trapeziometacarpal joint. Clin Orthop Relat Res. 1970;70:191-9.

22. Dell PC, Muniz RB. Interposition arthroplasty of the trapeziometacarpal Joint for osteoarthritis. Clin Orthop Relat Res. 1987;(220):27-34.

23. Gerwin M, Griffith A, Weiland AJ, Hotchkiss RN, McCormack RR. Ligament reconstruction basal joint arthroplasty without tendon interposition. Clin Orthop Relat Res. 1997;(342):42-5.

24. Kuhns CA, Emerson ET, Meals RA. Hematoma and distraction arthroplasty for thumb basal joint osteoarthritis: a prospective, single-surgeon study including outcomes measures. J Hand Surg Am. 2003;28(3):381-9.

25. Murley $\mathrm{AH}$. Excision of the trapezium in osteoarthritis of the first carpo-metacarpal joint. J Bone Joint Surg aM 1960;42:502-7.

26. Iyer KM. The results of excision of the trapezium. Hand. 198;13(3):246-50.

27. Jebsen RH, Taylor N, Trieschmann RB, Trotter MJ, Howard LA. An objective and standardized test of hand function. Arch Phys Med Rehabil. 1969;50(6):311-9.

28. Sollerman C, Ejeskär A. Sollerman hand function test. A standardised method and its use in tetraplegic patients. Scand J Plast Reconstr Surg Hand Surg. 1995;29(2):167-76.

29. Manske PR. Commentary: Excision of the trapezium. J Hand Surg Am. 2004;29(6):1078-9.

30. Pardini Junior AG, Freitas AD, Chaves AB, Freitas MB. Estudo comparativo entre ressecção do trapézio e interposição tendinosa com e sem ligamentoplastia no tratamento da artrose carpometacarpiana do polegar. Rev Bras Ortop. 2008;43(3):69-75.

Rev Bras Ortop. 2011;46(1):75-82 